\title{
A Multidisciplinary, Collaborative, Inter-agency and Comprehensive Approach for the Control of Chagas Disease as a Public Health Problem in Guatemala.
}

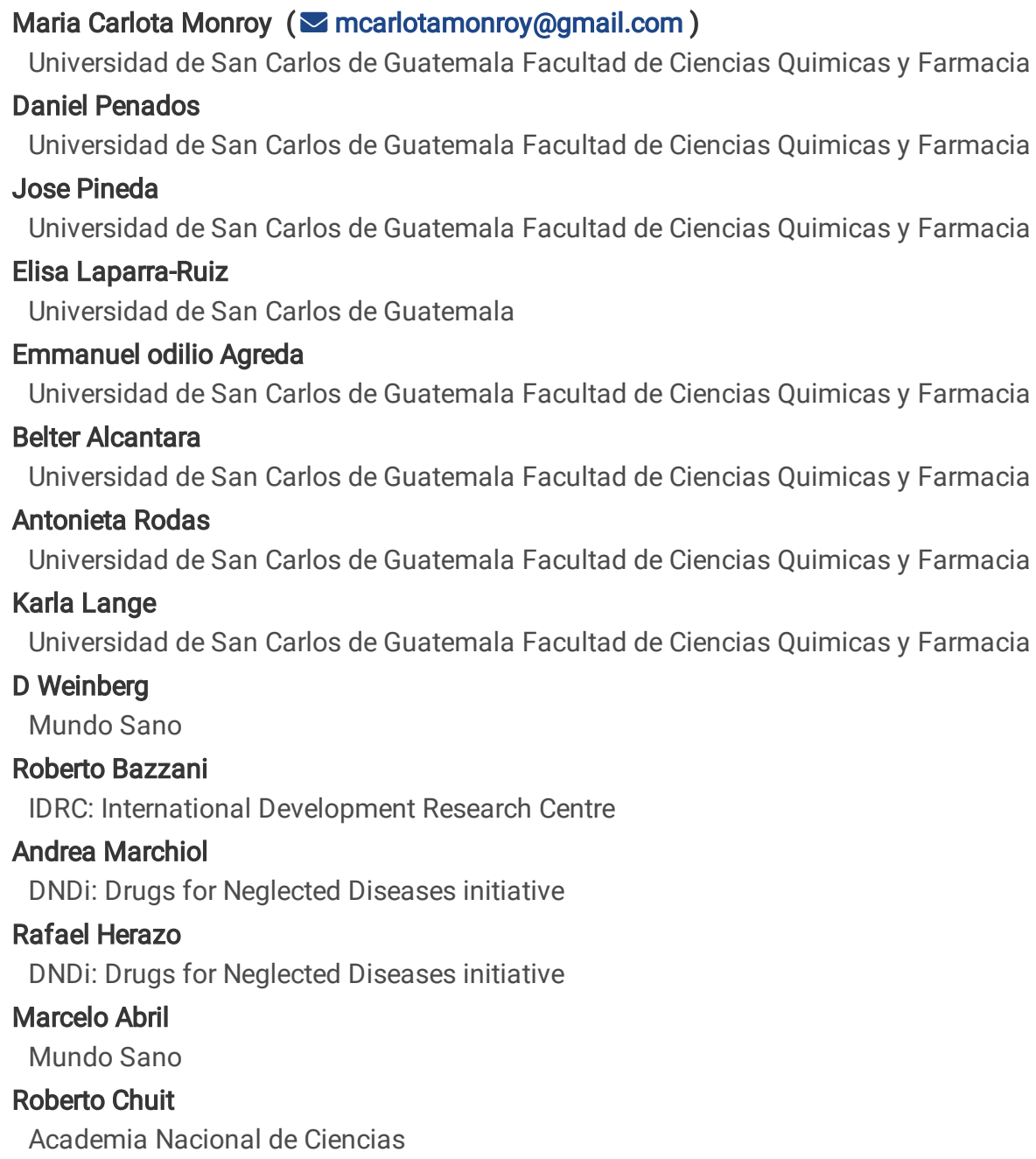

\section{Research Article}

Keywords: Chagas disease, collaborative control approach, Community participation, native vector, Central America

Posted Date: April 13th, 2021

DOI: https://doi.org/10.21203/rs.3.rs-400192/v1

License: (c) This work is licensed under a Creative Commons Attribution 4.0 International License. Read Full License

Version of Record: A version of this preprint was published at Acta Tropica on January 1st, 2022. See the published version at https://doi.org/10.1016/j.actatropica.2021.106157. 


\section{Abstract}

Background : Central America is considered a hotspot for Chagas disease transmission and the most important vector in the northern region is Triatoma dimidiata; a native vector adapted to multiple environments, including intra domestic and peri-domestic habitats. Chagas Disease is the leading cause of death associated with heart disease in Latin America, affecting mostly low-resources populations and the presence of the vector is associated to poor house constructions.

Methods: A multi-institutional project named "Alliances for the elimination of Chagas in Central America" was created to help reduce the incidence of the disease in the region. Each institution performing specific role including aspects of vector control, quality of housing, surveillance implementation, diagnosis and treatment of individuals, health promotion, and training of human resources.

Results: Eleven villages were entomologically evaluated; five villages were found to have high infestation rates ( $>20 \%)$, three had average infestation rates $(10-20 \%)$ and three had low-infestation rates $(<10 \%)$, coinciding with the type of risk-dwelling found in each of one. Additionally, all the villages had colonization rates greater than $50 \%$, and several showed important levels of triatomine overcrowding. This high colonization dynamic represents a high risk of vector transmission of Chagas disease; it was necessary to improve the household so as to make them refractory to infestation, reducing those characteristics that are appropriate for colonization. Serological tests carried out in two of the 11 villages showed that children under five years of age were not infected and the prevalence of infection was higher in women than men, showing the importance of women in the disease transmission dynamics, making education and empowerment directed towards women critical for transmission control.

Conclusion: Several institutions working together with specific roles promotes the community partition in several activities as vector control and patience attendance. Some epidemiological factor of the native vector was described.

Trial registration: The study received clearance from San Carlos University bioethics committee, Guatemala City, Guatemala (AC-010-2018).

\section{Introduction}

Chagas disease is the leading cause of death associated with heart disease in Latin America (1), with more than 8 million people at risk (2). Central America and Mexico have always been endemic areas for Chagas disease, with the presence of a diversity of native Triatomine species, vectors of Trypanosoma cruzi, among which Triatoma dimidiata stands out, given its important ability for colonizing domestic and peri-domestic habitats. Additionally, during the 20th century, an accidental circumstance led to the introduction of an important allochthonous species in the region, originally from the north of South America, Rhodnius prolixus (3). This introduction increased the number of cases, due to the better vector competence and domiciliation of this species, until its control / elimination during the first decades of the 21st century (4). This was achieved through international programmatic actions and cooperation among countries, within the framework of the Chagas Control Initiative in Central America and Mexico (IPCAM).

Currently, R. prolixus has been eliminated as a public health problem in El Salvador, Nicaragua, Guatemala, Honduras, Mexico, Costa Rica, and Belize, but the native species, Triatoma dimidiata is currently the vector responsible for transmission in the area. At the XVI Meeting of the IPCAM, the space shared by Guatemala and El Salvador was defined as a high-risk area "hotspot" which should be prioritized and addressed to achieve control of Chagas disease in the region (5). Based on this scenario, an inter-institutional agreement was signed between different public and private organizations. As part of this agreement, a project was elaborated with the objective of contributing to the elimination of Chagas disease as a public health problem in the geographical area of greatest transmission in Guatemala through the development of tools and methodologies that can be used in Central America to control transmission; under the name "Alliances for the elimination of Chagas in Central America". This association, of national and international institutions, allowed complementary actions based on the experience and specialization of each organization, that addressed most of the aspects which contribute to the presence of the disease in the region: personvector-environment-habits-behavior, in a comprehensive approach for the elimination of Chagas disease as a public health problem.

The transmission of Chagas disease is complex, and it is influenced by ecological, and socioeconomic aspects that need to be taken into consideration for its comprehensive control. In the vector domestic cycle, which results from the permanence and reproduction of triatomines inside the home and peri-domestic areas, elimination requires vector control mechanisms based on household risk factors which take into consideration vector dynamics, physical characteristics of homes, and cultural practices within the home (6). The characteristics and structure of the community is also important in order to develop participatory surveillance activities (vector findings, search and follow-up of positive patients), as well as adequate environmental management. In the mother-to-child transmission cycle, improvement in access to adequate medical care is required (7-9). Finally, appropriate care of any infected person is needed and may be achieved through early diagnosis, antiparasitic agents and/or appropriate medical treatment that can prevent or delay the progression of complications of chronic Chagas disease, significantly mitigating morbidity (10). 
Access to diagnosis, treatment and comprehensive care is limited by a number of factors that need to be identified in order to act in consequence and implement strategic approaches that promote the removal of barriers to health care. The aim of this study is to present the Alliances Project and the preliminary results of the baseline implementation performed in Guatemala which included aspects of vector control, quality of housing, surveillance implementation, diagnosis and treatment of individuals, health promotion, and training of human resources that will serve for the development of tools, methodologies and the intervention evaluation at different points throughout project implementation.

\section{Methodology Study area}

The Municipality of Comapa (Jutiapa Department) is located on the Guatemala-Salvador border (Fig. 1) and is part of the region defined as a "hotspot" of importance for the control of Chagas disease in the region, shared between Guatemala, El Salvador and Nicaragua (Pan American Health Organization/World Health Organization (PAHO/WHO IPCAM) Costa Rica 2015, PAHO/WHO IPCAM Panamá 2017). Its geography corresponds to subtropical dry forest, predominantly deforested by the change of land use for productive activities such as monocultures and grasslands for livestock $(11,12)$. It has an average elevation from 540 to 1350 meters above sea level and temperatures ranging from $22^{\circ} \mathrm{C}$ to $32^{\circ} \mathrm{C}(14.11328 ;-89.914811)(13)$.

Jutiapa has been characterized by the Ministry of Public Health and Social Assistance of Guatemala (MSPAS) among one of Guatemala's department with a high epidemiological risk for Chagas disease due to its high levels of infestation documented by the usual re-infestations after vector control with insecticide (14). Comapa has sociodemographic characteristics that also contribute to its high risk classification, including the highest rate of illiteracy among all the municipalities of Jutiapa, and most of its population lives in the rural area under high poverty conditions (72\%), with more than a quarter of them in extreme poverty (15).

Field actions were performed during 2018 and 2019 in 11 villages in the municipality of Comapa: Anonito, Matochal, San Cristóbal, San Antonio, Ixcanal I, Ixcanal II, San Ramón, El Naranjo, Piedra Pintada, El Pinito and San Miguel (Fig. 1), with a population of 6,096 people, distributed in 1,311 homes.

Through multidisciplinary and inter-agency work, secondary information was also gathered through surveys (entomological, social), primary prevention actions (spraying, house improvement), secondary prevention actions (activities to strengthen local capacities to detect, diagnose and treatment of patients), health promotion and human resources training (community activities, workshops, diplomas, trainings and consultancies). This work was performed by the different participating institutions which coordinate each activity through Framework Conventions for Technical Cooperation between MSPAS, and two of the non-governmental associations (NGOs) that participate in the project (Annex 1); Fundación Mundo Sano (FMS) and Drugs for Neglected Diseases initiative(DNDi).

\section{Household surveys and definition of risk}

All the houses in the area were registered and georeferenced by the Laboratory of Applied Entomology and Parasitology, University of San Carlos of Guatemala (LENAP-USAC). Moreover, the characteristics of the household (sleeping areas, warehouses, kitchen, etc.) were recorded by direct observation. Even empty, abandoned, houses under construction or reluctant homes were visited and recorded during either primary or secondary prevention actions. Additionally, the head of the family or elderly person was interviewed in order to learn about Capacities, Attitudes and Practices (CAP) related to vector transmission of the disease.

\section{Definition of home risk factors}

Based on survey data, houses were categorized according to risk into three types, A, B or C. This classification is based on the obtained score for risk of infestation using variables proposed through previous research carried out in Guatemala and Central America (6, 14). The risk categorization facilitated the field control processes. Table 1 details the variables considered as well as the assigned scores for each characteristic in order to categorize the houses into the three different types.

\section{Preventive actions}

The different actions performed may be divided as those that are related to primary prevention and those related to secondary prevention.

\section{Primary prevention}

Vector surveillance and control: An entomological Survey (ES) was conducted by the Vector Control Unit (ETV-MSPAS) based in Jutiapa on the same day in two different times: in Time 1, the man/hour methodology for the active search of kissing/triatomine bugs in homes with the 
help of tweezers and a flashlight (16) and in Time 2, vectors were searched for and captured after 20 minutes of insecticide application. A house is considered positive if a vector is captured during either Time.

Table 1

Risk variables for Triatoma dimidiata infestation. Housing risks are categorized into categories: A (low risk) $\leq 2.5$ points; B (average risk) $\leq 4.4$ points; and $\mathrm{C}$ high risk $\geq 4.5$ points

\begin{tabular}{|l|l|}
\hline Variable & Points \\
\hline Walls built with traditional bajareque (sticks and straws intertwined with mud) or adobe with the presence of cracks & 3.5 \\
\hline Presence of triatomine bugs or any of their traces (i.e. fresh or old feces, exuviae) & 1.5 \\
\hline Chicken coop inside the house or attached to one of the walls of the household & 1.0 \\
\hline Presence of wood or firewood inside the household & 1.5 \\
\hline Presence of construction materials inside the household & 0.5 \\
\hline House constructed more than 6 years ago & 0.5 \\
\hline Visible accumulation of objects or clutter & 0.5 \\
\hline Presence of a dirt or badly broken floor & 0.5 \\
\hline
\end{tabular}

Collected live specimens were placed in mesh-covered plastic bottles labeled with house identification number, house chief, date, and ecotope (intra or peridomicile) and number of specimens collected. Approximately 5 to 8 hours post field collection, the samples were transferred to individual, properly identified vials with $95 \%$ ethanol for their preservation, with capture and demographic information (sex or life stage and whether it appeared engorged or not, indicating if it had fed recently) recorded in a notebook and an electronic database.

The data obtained on paper was digitized in Microsoft Excel sheets and subsequently uploaded to a Data Management Platform, which also allows uploading the geolocation of the households and the associated epidemiological information in a Geographic Information System (GIS).

\section{Entomological Indices}

Several entomological indexes were used to evaluate the infestation situation of each household, including: the infestation rate which is the number of infested homes divided by the total homes inspected, multiplied by 100; the overcrowding rate which is the number of triatomine bugs captured divided by the total number of infested homes; the colonization rate, which is the number of infested houses with the presence of nymphs divided by the total number of infested homes, multiplied by 100; and finally the visitation rate, which is the number of infested houses with only the presence of adult triatomine bugs, divided by the total number of infested homes, multiplied by 100 .

A pyrethroid insecticide spraying of all homes was performed, regardless of the house risk category (A, B or C). Beta Cypermethrin (SipertrinAsimethrin 5g, Chemotecnica, Argentina) solution was used at a concentration of $5 \%$ of 50 mg per square meter on the wall with a Hudson manual pump. Ten to 20 minutes after spraying, all of the triatomines that escaped from their hiding/refuge spots were collected as specified above.

\section{House improvement and environmental management}

House improvement is based on community participation for the organization and development of activities and the improvements themselves. House improvements include covering and avoiding the formation of cracks in the walls using local materials (i.e. river sand, lime and select fill materials), and replacement of the floor with cement like material instead of dirt $(17,18)$. The materials needed were provided in part by the authorities of the Municipality of Comapa and in part by the inhabitants of the community themselves. Both the community members and authorities were trained in the different house improvement techniques while project staff monitored, guided, and recorded the improvements.

Besides the house improvements, environmental management was accomplished with community participation capacitation, as is explained by Soto et. al. (2019). The community received information about the risk of maintaining animals, accumulated objects, firewood, and construction materials inside the house, and were instructed to relocate them in the peridomicile, away from the house walls, especially if they are bajareque or adobe walls (19).

\section{Secondary prevention}


Serological study. Two villages with the highest rate of vector infestation were selected to begin sampling for the serological study: Anonito and Matochal. Sampling was carried out together with the collaboration of bachelor students from Biological Chemistry (Department of Cytohistology, School of Pharmacy, University of San Carlos of Guatemala (DC-USAC)). The community was informed in advance of the benefits and risks of the activity, as well as the objectives of the study, the procedure and the timing of the sampling. The study was approved by the Ethics Committee of the University of San Carlos (approval AC-010-2018) together with an epidemiological data sheet for each family. Additionally, informed consents were obtained from all those individuals that were interested in participating, including informed assent from under aged children.

Blood was drawn through venipuncture ( $5 \mathrm{ml}$ total) and the serum was separated and transported refrigerated to the USAC to determine the presence of anti-T. cruzi antibodies by Indirect Hemagglutination (HAI). All positive samples and $10 \%$ of negative samples were additionally evaluated by Enzyme-Linked ImmunoSorbent Assay (ELISA) (Wiener Laboratorios SAIC, Argentina). Those samples with discordant results were confirmed by recombinant ELISA (Wiener Laboratorios SAIC, Argentina). An individual was considered positive if two of the tests performed were positive (HAl and one of the two ELISA methods) and those samples were processed by a semi-qualitative HAI to determine the antibody title. These confirmed positive samples and $10 \%$ of negative samples were further confirmed by the National Health Laboratory (LNS-MSPAS). Once the results were confirmed by the LNS, they were transferred to the Jutiapa Health Area (DASJ) to coordinate the initiation of treatment. The delivery of results to communities was carried out by DASJ staff. The results obtained were then included in the epidemiological data sheets to perform the analysis of the association between infection and the variables recorded. Lastly, all positive patients were referred to the health system where they received comprehensive care.

Seminar for the identification of access barriers: In order to analyze the factors that act as barriers to the diagnosis and treatment of Chagas Disease in the area, a seminar was offered to the health care officials (professionals, technicians and support personnel) from all Guatemala regions. Barriers refer to any factor that limits or inhibits patient access to diagnosis, treatment and/or clinical management of Chagas Disease (20). The aim of the seminar was to identify barriers to comprehensive people's care based on a participatory technique, concretely on the challenge model (Management Sciences for Health, 2009). Working groups were established and distributed into 4 themes: 1 ) Diagnosis;

2) Treatment; 3) Epidemiological and entomological surveillance and; 4) Congenital transmission. The working groups determined the obstacles to each of the discussion components, as well as prioritized and classified them according to established categories.

\section{Development of a Chagas Disease roadmap for patient care}

In order to contribute to the development of a roadmap for the Chagas Disease patients in Guatemala, some elements of the methodology used by the Colombian Ministry of Health for the development of Integral Routes of Care (RIA) were used. These are tools of articulation and institutional organization that are used to define conditions necessary to ensure the integrality of care by the agents of the Health System and other sectors (21). For this project, nine steps from the original method were adjusted

Step 1: Formation of a working group (health areas and central level of MSPAS) to determine the scenarios to be answered by the RIA (acute Chagas, blood bank, chronic Chagas and Chagas in the mother/child binomial); Step 2: Identification of interventions taking into account the barriers identified in the barriers seminar; Step 3: Review of the interventions currently implemented; Step 4: Review of the current standard of care; Step 5: Preliminary diagram of the interventions according to the scenario; Step 6: Construction of an intervention matrix; Step 7: Graphical construction of the RIA; Step 8: Validation and feedback; Step 9: Implementation (the start of the pilot is pending).

\section{Results}

The results of this first interventions and baseline study corresponds to the 11 communities mentioned above that were used to evaluate the methodology and write operational guidelines for both primary and secondary prevention.

\section{Primary prevention actions}

Through the household visits and inspections performed in the study area, a total of 1,572 dwellings were registered, 1,311 (83.4\%) were assessed, 175 (11.13\%) were uninhabited and 62 (4.26\%) were closed (Table 2). Only 10 of the visited homes (0.7\%) rejected domiciliary inspection. The values of home evaluation varied from one village to another, with high values of acceptance in Piedra Pintada (98\%), Matochal (90.3\%), and San Miguel (89.1\%) and lower values of surveyed homes in San Antonio (72.1\%), Ixcanal II (73.4\%), and San Cristobal (75\%) 
Table 2

Details of homes surveyed and not surveyed in the 11 villages of Comapa,

\begin{tabular}{|llllll|}
\hline Village & Surveyed & Closed & Uninhabited & Total & Participation \\
\hline Anonito & 184 & 4 & 21 & 211 & $87.2 \%$ \\
\hline Matochal & 65 & 2 & 4 & 72 & $90.3 \%$ \\
\hline San Miguel & 180 & 9 & 12 & 202 & $89.1 \%$ \\
\hline El Naranjo & 52 & 5 & 5 & 62 & $83.9 \%$ \\
\hline San Ramon & 104 & 5 & 16 & 126 & $82.5 \%$ \\
\hline Ixcanal I & 136 & 5 & 18 & 160 & $86.3 \%$ \\
\hline San Antonio & 75 & 17 & 12 & 104 & $72.1 \%$ \\
\hline El Pinito & 47 & 8 & 1 & 56 & $83.9 \%$ \\
\hline Ixcanal II & 141 & 4 & 41 & 192 & $73.4 \%$ \\
\hline San Cristobal & 174 & 8 & 43 & 232 & $75.0 \%$ \\
\hline Piedra Pintada & 153 & 0 & 2 & 155 & $98.7 \%$ \\
\hline Total & 1311 & 67 & 175 & 1572 & $83.4 \%$ \\
\hline
\end{tabular}

Based on the home inspections and surveillance, the geographic distribution of $T$. dimidiata infestation showed a heterogeneous pattern as can be observed by the entomological indices of the 11 villages, detailed in Table 3. Five of the villages had an infestation rate greater than $20 \%$ which, for this project, is considered to be a high infestation rate: Anonito, Matochal, San Antonio, Ixcanal II, and Piedra Pintada. The villages identified as having an average infestation rate (10\% - 20\%) were Ixcanal I, El Pinito, and San Cristobal, and those identified as having a low-infestation rate (less than 10\%) were San Miguel, El Naranjo and San Ramón. It is important to mention that all the villages included in the study had a colonization rate greater than $50 \%$. Most villages even had colonization rates that were greater than $75 \%$. It is also important to note that several villages showed important rates of overcrowding of triatomine bugs in the household, like El Naranjo (10.7), San Antonio (10.2) and Matochal (8.7). Finally, the highest visitation rates of triatomine bugs were found in the villages of San Miguel (50.0\%), Piedra Pintada (35.1\%), and Ixcanal I (33.3\%).

Table 3

Entomological indices calculated for Triatoma dimidiata in 11 villages in the Municipality of Comapa.

\begin{tabular}{|llllll|}
\hline Villages & Homes Surveyed $(\mathbf{N})$ & $\begin{array}{l}\text { Infestation rate } \\
(\%)\end{array}$ & Overcrowding rate & Colonization index & Visitation rate \\
(\%) & $(\%)$ & 77.8 & 22.2 \\
\hline Anonito & 183 & 34.4 & 4.7 & 77.3 & 22.7 \\
\hline San Miguel & 181 & 33.3 & 8.7 & 50.0 & 50.0 \\
\hline El Naranjo & 52 & 4.4 & 1.9 & 100.0 & 0.0 \\
\hline San Ramon & 105 & 5.8 & 10.7 & 87.5 & 12.5 \\
\hline Ixcanal I & 136 & 7.6 & 2.3 & 66.7 & 33.3 \\
\hline San Antonio & 74 & 15.4 & 3.5 & 77.3 & 22.7 \\
\hline El Pinito & 50 & 29.7 & 10.2 & 100.0 & 0.0 \\
\hline Ixcanal II & 141 & 10.0 & 7.6 & 76.3 & 23.7 \\
\hline San Cristobal & 177 & 27.0 & 4.0 & 78.6 & 64.9 \\
\hline Piedra Pintada & 153 & 15.8 & 24.2 & 5.9 & 35.1 \\
\hline
\end{tabular}

Infestation rate $=($ Infested homes $/$ total homes inspected $) \times 100$. Overcrowding rate $=$ Triatomine bugs captured/total infested homes . Colonization index $=$ (Houses with nymphs / total infested homes) $\times 100$. Visitation rate $=($ Homes with only adult triatomine bugs/total infested homes) $\times 100$. 
Table 4 presents the results of participation in wall and floor improvement activities in the different villages at the time of the entomological evaluation. The villages with the greatest participation for home improvement were Piedra Pintada and Matochal, both with 79\% participation, followed by Ixcanal II (70\%) and San Miguel (68\%). The villages with the lowest percentage of participation were El Pinito (45\%), San Antonio (42\%) and San Cristobal (21\%).

Table 4

Assessment of homes at risk of Triatoma dimidiata infestation in the 11 villages of the Municipality of Comapa included in the study and percentage of improvements

\begin{tabular}{|lllll|}
\hline & \multicolumn{5}{c}{ Homes at risk } & \multicolumn{3}{l|}{ Improvement in at-risk housing (B and C) } \\
& (Categories B and C) & & \\
\hline Village & N houses & $\%$ & N houses & 55 \\
\hline El Naranjo & 40 & 77 & 22 & 42 \\
\hline San Antonio & 55 & 73 & 23 & 45 \\
\hline El Pinito & 22 & 47 & 10 & 79 \\
\hline Matochal & 38 & 58 & 30 & 66 \\
\hline Ixcanal I & 107 & 79 & 71 & 79 \\
\hline Piedra Pintada & 118 & 77 & 93 & 70 \\
\hline Ixcanal II & 98 & 70 & 69 & 54 \\
\hline San Ramon & 56 & 54 & 30 & 48 \\
\hline Anonito & 121 & 65 & 59 & 68 \\
\hline San Miguel & 112 & 62 & 76 & 21 \\
\hline San Cristobal & 81 & 47 & 17 & \\
\hline
\end{tabular}

\section{Secondary prevention actions}

The results of the serological analysis performed in the villages of Anonito and Matochal (Table 5) showed participation percentages of 71.8\% (619 participants/861 inhabitants) and 72.8\% (193 participants/265 inhabitants), respectively. Anonito had a higher percentage of positive individuals, with a total seroprevalence of $7.3 \%$, compared to Matochal which had a seroprevalence of $3.6 \%$. In both villages the percentage of positive women was higher than that of men: in Anonito 5.3\% of positive individuals were women and $1.9 \%$ were men, while in Matochal $2.6 \%$ were women and $1.0 \%$ were men. Finally, in both villages, none of the children under 5 years of age were found to be infected. Nonetheless, Anonito presented positive results in individuals from the age range of 6 to 14 years, while Matochal only presented positive individuals from the range of 21 to 40 years of age. 
Table 5

Results of the serological tests carried out in the villages of Anonito and Matochal.

\begin{tabular}{|c|c|c|c|c|}
\hline \multicolumn{5}{|l|}{ Anonito Village } \\
\hline \multirow{2}{*}{$\begin{array}{l}\text { Age range } \\
\text { (years) }\end{array}$} & \multicolumn{2}{|c|}{ N positive individuals (\%) } & \multirow[t]{2}{*}{ Total N positives (\%) } & \multirow[t]{2}{*}{ Total $\mathrm{N}$ of individuals tested } \\
\hline & Females & Males & & \\
\hline $0-5$ & $0(0)$ & $0(0)$ & $0(0)$ & 99 \\
\hline $6-14$ & $3(1.5)$ & $1(0.5)$ & $4(2.0)$ & 202 \\
\hline $15-20$ & $1(1.9)$ & $1(1.9)$ & $2(3.7)$ & 54 \\
\hline $21-40$ & $11(7.5)$ & $5(3.4)$ & $16(10.9)$ & 147 \\
\hline$>41$ & $18(15.4)$ & $5(4.3)$ & $23(19.7)$ & 117 \\
\hline Totals & $33(5.3)$ & $12(1.9)$ & 45 (7.3) & 619 \\
\hline \multicolumn{5}{|l|}{ Matochal Village } \\
\hline \multirow[t]{2}{*}{ Age range (years) } & \multicolumn{2}{|c|}{ N positive individuals (\%) } & Total N positives (\%) & Total $\mathbf{N}$ of individuals tested \\
\hline & Females & Males & & \\
\hline $0-5$ & $0(0)$ & $0(0)$ & $0(0)$ & 29 \\
\hline $6-14$ & $0(0)$ & $0(0)$ & $0(0)$ & 46 \\
\hline $15-20$ & $0(0)$ & $0(0)$ & $0(0)$ & 19 \\
\hline $21-40$ & $4(7.8)$ & $1(2.0)$ & $5(9.8)$ & 51 \\
\hline$>41$ & $1(2.1)$ & $1(2.1)$ & $2(4.2)$ & 48 \\
\hline Totals & 5 (2.6) & $2(1.0)$ & $7(3.6)$ & 193 \\
\hline
\end{tabular}

Participation in the seminar carried out for identification of access barriers to the diagnosis and treatment of Chagas Disease in the area involved $90 \%$ of the units which work with Chagas Disease Care in the country from both the national (MSPAS) and departmental (DASJ, Chiquimula Health Area) health sectors. An organization from the civil society (Community Leaders of Comapa), other local Institutions (LENAP/USAC) and international partners (FMS, DNDi) also participated.

The barriers identified in the seminar are described in Table 6. According to the participants of the seminar, the main barriers to access to diagnosis are process centralization, the lack of professional and specific training and the lack of socialization of regulations. With regard to the main barriers to treatment, outdated protocols, lack of trained personnel, delays in diagnostics and lack of equipment and reagents for clinical evaluation prior to etiological treatment were the ones identified as most important. With regard to epidemiological surveillance, the participants agreed that main barriers included the fact that Chagas Disease did not stand out as a priority for guidelines, the centralization of health services, and the lack of comprehensive information in the community (i.e. Effect of deforestation and hygiene). Finally, specifically with respect to congenital transmission, excessive bureaucracy, lack of information records, lack of parental screening processes, and lack of perception of risk and education in the community were identified as the main barriers. 
Table 6

Barriers to the diagnosis and treatment of Chagas disease in Guatemala identified through a specific seminar given to health effectors.

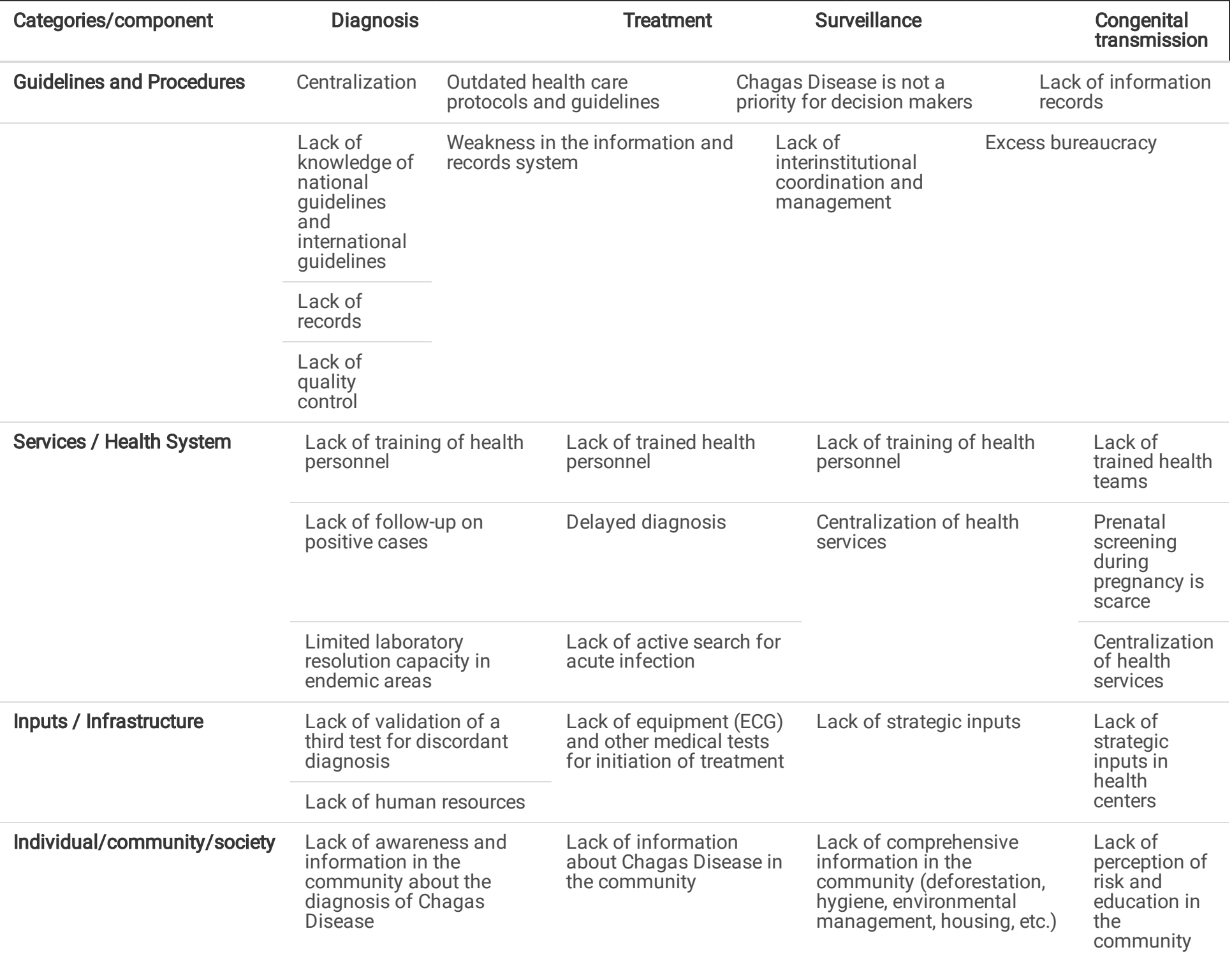

Table 6. Barriers to the diagnosis and treatment of Chagas Disease in Guatemala identified through a specific seminar given to health effectors.

Regarding the RIA construction process, the following advances were made: A) a workshop was carried out with 36 individuals, representing 11 endemic Health Areas and the central level in order to determine the scenarios to be answered by the RIA (acute Chagas, blood banks, chronic Chagas and Chagas in the mother/child binomial). B) Construction of the first version of four RIA's (acute and chronic Chagas, blood bank and pregnancy/newborn care) including a matrix of intervention for each one.

\section{Discussion}

There exists broad consensus on the benefits of teamwork to improve the quality of life of individuals, families and the community. Working in the community in an interinstitutional, cross-sectoral, multidisciplinary and collaborative manner produces irrefutable benefits and improvements in the quality of physical, mental and social health (22). A systemic vision to tackle different problems from various points of view enables the implementation of more effective actions (23). The project Alliances implemented in Guatemala by different national and international institutions in partnership has already allowed setting the baseline in the Municipality of Comapa (MC) in order to be able to then expand to other municipalities and eventually measure the impact of the project throughout its duration.

Through the entomological evaluation conducted in the first 11 communities of Comapa, variations in the indices were found. Most variations were associated with the rates of vector infestation and coincided with the calculated risk obtained for each of the households. High infestation values (greater than 20\%) coincide with a greater than $40 \%$ presence of type C dwellings in the village (Table 4 ). This is consistent 
with the presence of risk variables such as cracked walls, animals inside the house, disorder, firewood or construction materials accumulated in the inside of the household, and dirt floors, increasing the possibility of presenting infestation in the houses $(6,14)$.

Ixcanal I village had a high percentage of type $\mathrm{C}$ dwellings and an average infestation rate of $15.4 \%$. The visitation rate in Ixcanal I was among the highest of all villages, representing a highly mobile population of triatomine bugs, possibly from colonized dwellings to other non-infested dwellings. This evidences the important influence of colonized dwellings, with active reproduction processes, on non-infested dwellings, highlighting the high risk that these houses pose for the entire village (24). On the other hand, it is important to note that there are two villages, San Miguel and El Naranjo, which present more than $40 \%$ of type C housing, yet their infestation values are less than $10 \%$. This might be due to altitude distribution of $T$. dimidiata, where the highest density values are usually found between 1000 to 1400 meters above sea level and the lowest at an altitude of 500 to 700 meters above sea level, which is the altitude of both San Miguel and El Naranjo (25).

Intra-domiciliary infestation is the main pattern for concern in all the 11 villages; however, the colonization rates greater than $50 \%$, which is a measure of the active reproduction of the vector within the house, represent triatomine bug populations which are highly adapted to the household $(12,26,27)$. This high colonization dynamic represents a high risk of vector transmission of Chagas disease; therefore, it is necessary to improve the household so as to make them refractory to infestation, reducing those characteristics that are appropriate for colonization and maintenance of the bugs within the house (ie. presence of cracked walls, animals within the household and dirt floors). Reducing the presence of these household characteristics would enable reducing the risk of transmission of Chagas disease in the region (18, 28). To reduce this and other risk factors in all the villages, a comprehensive intervention, based on education and community work, is needed to ensure a long-term solution to prevent the infestation of T. dimidiata $(19,28)$. The selective insecticide spraying performed in the last 10 years in Jutiapa must be evaluated and complemented with the removal of intra domiciliary risk factors.

Given the high number of high-risk homes (type C) present in the villages, strengthening the value of community participation for the improvement of houses to lower the risk of infestation is important. However, it is also important to consider that the time it takes for each village to achieve housing improvement is different, depending on the time of year, the ease of work and the availability of materials in each village. This is reflected in the varying attitude of the inhabitants towards the entomological control actions and the percentage of houses that were improved in each village. For example, San Cristóbal was the town with the least participation in the improvement of houses. However, it also had the highest proportion of type A households, which were not prioritized during the housing improvement activities, since they are the houses with the least risk of being infested by $T$. dimidiata. Type A houses are made mostly of brick blocks and therefore no cracks are found in the walls.

El Naranjo was the most difficult to provide and transfer materials due to access roads and weather conditions, lowering its participation in house improvement activities. The good reception during the entomological survey could explain the overall good participation percentage in the villages and could be used as an indirect indicator to measure the willingness to participate in home improvement as well as other activities. The importance of community participation in an innovative management is here enhanced (29).

Community participation in house improvement in the study area was higher than the one obtained before in other villages, such as La Brea and El Tule, where $46 \%$ and $30 \%$ participation was reported (28). Other ethnic groups in Guatemala, such as the Chortí, had low community participation in house improvement activities, with $45 \%$ of B and C risk category houses improved (19). Other studies in Guatemala, El Salvador and Honduras have reported that between 20 and $30 \%$ of the inhabitants of different villages carry out home improvements on their own and by their own means (14). Another study performed in three villages in Guatemala reported that $62 \%$ of the homes evaluated had made partial improvements and only $17 \%$ had made complete improvements (30), but in this study, the improvements were performed by the institution in charge of the study and not by the community. The high participation percentages obtained for the current study, as well as those reported by Monroy et al. (2009), show that inter-institutional and multidisciplinary cooperation allows reaching the population more effectively and therefore obtaining better results.

Removing risk factors from homes or making home improvements requires at least two weeks of work, which is time-consuming for families. The most frequent economic activity in the area is agriculture, so the sowing and harvesting seasons are very important for the inhabitants. Because of this, it is necessary for the home improvement to take place in a timely window of time, in which residents could have additional time to work on the houses. In the localities where there were delays in the delivery of materials for housing improvement (El Naranjo), there was an overlap between the planting season and the housing improvement actions, which meant that the neighbors could not apply these actions in an efficient time, therefore, this was reflected in low community participation. Another important factor to achieve housing improvement is the union of family efforts between men and women (31), so it is essential to detect indicators for families which present more difficulties to participate, with the objective of giving support and performing follow-up activities in order to engage them more effectively and transforming them into more proactive participants in their health. Social innovation (29) and comprehensive educational actions (19) are recognized as important tools for risk removal factors in the house for reducing T. dimidiata infestation. 
Regarding the seroprevalence obtained for Anonito and Matochal villages, participation was greater than $70 \%$, which is higher than what has been previously reported in these communities (32), showing that the community awareness processes were appropriate. The seroprevalence found in each of the villages, $7.3 \%$ for Anonito village and $3.6 \%$ for Matochal, are consistent with the prevalence of $8.0 \%$ previously found in Anonito for women of childbearing age in two homestead farms from El Carrizo Village, also located in Comapa (32). These similar results between the two villages, demonstrate the importance of women in the dynamics of disease transmission, since in the current study, women showed higher seroprevalence with respect to men. Moreover, this evidences the importance of education and empowerment in women in the community to ensure effective control of maternal and child transmission of the disease.

Additionally, a marked difference in the prevalence of the disease was observed between different age ranges, with more than $80 \%$ of the positive cases concentrated in individuals older than 21 years of age in Anonito and all the cases concentrated in adults in Matochal. This pattern has been previously observed in nearby communities(32) and is probably due to previous vector transmission by $R$. prolixus, since prior to certification of the elimination of transmission of the disease by this vector in 2008 (4), it was a more efficient vector than T. dimidiata (33). Finally, it is important to emphasize the absence of prevalence in children under 5 years of age for both villages, which had already been reported (34), generating evidence pointing to the inefficient vector transmission mechanisms of $T$. dimidiata for this age range given small children have more restricted movement and are closer to the mother. Another possible explanation of the phenomenon is the low vector capacity of T. dimidiata, so it takes many more years of human-vector contact for transmission to be effective (33).

During the barrier seminar for diagnosis and treatment of Chagas Disease, the high participation of all the actors involved was presented as an advantage, since all the participants are directly involved in diagnosis and treatment, facilitating the identification of barriers and decisionmaking. The identified barriers are similar to those found in other Latin American countries; where the centralization of services, mismanagement of information, and poor education in the population make it difficult to access diagnosis and treatment of the disease (35, 36). Inter-institutional cooperation work requires adequate coordination and effective communication between all parties, facilitating the fulfilment of the objectives set for the project. Interinstitutional, cross-sectoral and multidisciplinary work is necessary to enrich, strengthen and provide feedback for the project (37). An example of this was the barrier identification seminar for the diagnosis and treatment of Chagas disease, where multiple institutions (academic, governmental, and foreign entities) collaborated with a common goal, facilitating the articulation of information and decision-making.

Given that barriers were mostly related to low institutional articulation, thus creating difficulties at the planning stage for continuous and permanent actions due mainly to the lack of awareness of authorities and the centralization of information, a RIA for the population at risk was designed together with the authorities. This previously implemented strategy was successful in Colombia, promoting the decentralization of processes, raising awareness of authorities and helping to ensure access to health $(38,39)$. However, a number of discussions and validation of the Chagas RIAs are still pending, and a pilot project will be implemented in prioritized areas.

\section{Conclusion}

The participation of several institutions and partners leads people's confidence, facilitating the involvement of communities in diverse activities. During the activities mentioned herein, the high participation and involvement of communities was highlighted, with $82 \%$ participation in the entomological surveillance activities, more than $80 \%$ in the seroprevalence study, an average participation of $57 \%$ for house improvement activities (B and C categories), and a $90 \%$ participation in the barrier seminar. The sustainability of this inter-institutional intervention is based on the fundamental role of local institutions as well as communities and partners. In the study area, considered to be Guatemala's main hotspot, the first implementation of the project helped to set the baseline and identify areas that worked and those than need improvement in order to serve as a model for implementation in similar contexts in the rest of Guatemala and other countries of Central America, eventually making progress towards the elimination of Chagas as a public health problem.

\section{Abbreviations}

CAP: Capacities, Attitudes and Practices

DASJ: Jutiapa Health Area

DC-USAC: Department of Cytohistology, School of Pharmacy, University of San Carlos of Guatemala

DNDi: Drugs for Neglected Diseases initiative

ELISA: Enzyme-Linked ImmunoSorbent Assay

ES: Entomological Survey

Page $11 / 16$ 
ETV-MSPAS: Vector Control Unit, Ministry of Public Health and Social Assistance

FMS: Fundación Mundo Sano

GIS: Geographic Information System

HAl: Hemagglutination

LENAP-USAC: Laboratory of Applied Entomology and Parasitology, University of San Carlos of Guatemala

LNS-MSPAS: National Health Laboratory, Ministry of Public Health and Social Assistance

MC: Municipality of Comapa

MSPAS: Ministry of Public Health and Social Assistance

NGOs: non-governmental associations

PAHO: Pan American Health Organization

PCAM: Chagas Control Initiative in Central America and Mexico

RIA: Routes of Care

WHO: World Health Organization

\section{Declarations}

- Ethics approval and consent to participate

Study received clearance from San Carlos University bioethics committee, Guatemala City, Guatemala (AC-010-2018).

- Consent for publication

Not applicable

- Availability of data and materials:

available from corresponding author on request

- Competing interests

The authors declare that they have no competing interests

- Funding

Financial support:

- International Development Research Center (IDRC) (project 108651-001)

- Authors' contributions

- Monroy M.C: Project leader, data analysis, manuscript drafting, field work including entomological, serological, and seminar for diagnosis barriers.

- Penados D: Manuscript drafting, data analysis and platform data analysis designed, field work for entomological data and seminar for diagnosis barriers

- Pineda J: Manuscript drafting, data analysis and platform data analysis designed, field work for entomological data and seminar for diagnosis barriers

- Laparra-Ruiz E: In charge of interinstitutional cooperation, manuscript drafting, data analysis, field work for entomological data, serological data, and seminar for diagnosis barriers

- Agreda E.O: Manuscript drafting, data analysis and platform data analysis designed, field work for entomological data. 
- Alcantara B: Field operations leader, entomological survey, flush out activities and house improvement activities leader. Facilitator for serological analysis field activities.

- Rodas A: serological sampling, laboratory assays, data analysis.

- Lange K: serological sampling and laboratory assays, data analysis.

- Weinberg D: Participate in data analysis, flush out activities, and platform data analysis designed.

- Bazzani R: General advisor of the project and manuscript drafting

- Marchiol A: Coleader for seminar for Chagas diagnosis barriers, and data analysis

- Herazo R: Coleader for seminar for Chagas diagnosis barriers, and data analysis

- Salvatella Agrelo R: General advisor, selection of the initial working area.

- Abril M: General advisor, reviewing of the manuscript.

- Chuit R: General advisor, data analysis, flush out activities, and seminar for Chagas diagnosis barriers.

- Acknowledgements

We wish to express our gratitude to Cementos Progreso (CEMPRO) for the donation of native tree species for reforestation in some villages in Comapa; Loyola University (LOYNO) for the Academic exchange with LENAP-USAC on advice given for genetics issues; University of Vermont (UVM) for training and assisting USAC students with proteomics analysis (mass spectrometry) and managing funds for student exchange activities and establishing a nursery with native plants; Programa de Sistemas de Información para la Resiliencia en Seguridad Alimentaria y Nutricional de la Región del SICA (PROGRESAN-SICA) and Visión Mundial (VM) for improving houses in different communities of Jutiapa; Instituto de la Mujer, Universidad San Carlos de Guatemala (IUMUSAC) for planning and helping on the execution of leadership and entrepreneurship courses for women from Anonito and Matochal; Médicos con Iberoamérica (IBERMED) for the donation of equipment to monitor people with Chagas disease and constant training for health personnel. To the students of DC-USAC for their help in the serological data processing. We would also like to acknowledge Maria Victoria Periago from CONICET/FMS for editing and reviewing the language for the manuscript, as well as Sergio Sosa-Estani from DNDi, for overviewing the activities planned by DNDi.

- Authors' information

Affiliations

University of San Carlos of Guatemala, Faculty of Chemical Sciences and Pharmacy, School of Biology, Laboratory of Applied Entomology and Parasitology (LENAP-USAC), Guatemala City, Guatemala.

University of San Carlos of Guatemala, Faculty of Chemical Sciences and Pharmacy, School of Biological Chemistry, Department of Cytohistology, Guatemala City, Guatemala

Fundación Mundo Sano (FMS), Buenos Aires City, Argentina.

International Development Research Centre (IDRC), Canada.

Drug for Neglected Diseases initiative (DNDi), Rio de Janeiro, Brazil

Pan American Health Organization (PAHO/WHO), Uruguay

\section{References}

1. Chatelain E. Chagas disease drug discovery: Toward a new era. J Biomol Screen. 2015;20(1):22-35.

2. World Health Organization. The Weekly Epidemiological Record (WER) [Internet]. Vol. 6, Weely Epidemiological Record. 2015. p. 33-44. Available from: https://www.who.int/wer/en/\%0Ahttp://www.who.int/wer/en/

3. Dujardin JP, Muñoz M, Chavez T, Ponce C, Moreno J, Schofield CJ. The origin of Rhodnius prolixus in Central America. Med Vet Entomol. 1998;12(1):113-5.

4. Hashimoto K, Schofield C. Elimination of Rhodnius prolixus in El Salvador, Central America. Parasites and Vectors. 2012;5(45):1068-9.

5. Pons AL, González JA, Lara BD, Pérez OL, Lasso JI, Fernández NA. Décimo Sexta Reunión de la Comisión Intergubernamental de la Iniciativa de los Países de Centroamérica y México (IPCAM) para la Interrupción de la Transmisión Vectorial, Transfusional y Atención Médica de la Enfermedad de Chagas. IPCAM. Costa Rica; 2015.

Page $13 / 16$ 
6. Bustamante D, Monroy C, Pineda S, Rodas A, Castro X, Ayala V, et al. Risk factors for intradomiciliary infestation by the Chagas disease vector Triatoma dimidiata in Jutiapa, Guatemala Factores de riesgo para la infestación intradomiciliaria por el vector de la enfermedad de Chagas ,. Cad Saúde Pública, Rio Janeiro. 2009;1:83-92.

7. Zeledón R, Rojas JC. Environmental management for the control of Triatoma dimidiata (Latreille, 1811), (Hemiptera: Reduviidae) in Costa Rica: A pilot project. Mem Inst Oswaldo Cruz. 2006;101(4):379-86.

8. Balouz V, Agüero F, Buscaglia CA. Chagas Disease Diagnostic Applications: Present Knowledge and Future Steps. Adv Parasitol. 2017;97:1-45.

9. Ávila Montes G, Martínez Hernández M, Ponce C, Ponce E, Soto Hernández R. La enfermedad de Chagas en la zona central de Honduras: Conocimientos, creencias y practicas. Rev Panam Salud Publica/Pan Am J Public Heal. 1998;3(3):158-63.

10. Viotti R, Vigliano C, Lococo B, Bertocchi G. Annals of Internal Medicine Article Long-Term Cardiac Outcomes of Treating Chronic Chagas Disease with Benznidazole versus No Treatment. Ann Intern Med. 2006;144:724-34.

11. Griscom HP, Ashton MS. Restoration of dry tropical forests in Central America: A review of pattern and process. For Ecol Manage [Internet]. 2011;261(10):1564-79. Available from: http://dx.doi.org/10.1016/j.foreco.2010.08.027

12. Penados D, Pineda J, Catalan M, Avila M, Stevens L, Agreda E, et al. Infestation dynamics of Triatoma dimidiata in highly deforested tropical dry forest regions of Guatemala. Mem Inst Oswaldo Cruz. 2020;115(e200203):1-8.

13. INSIVUMEH. Normales Climáticas [Internet]. 2020. Available from: http://historico.insivumeh.gob.gt/normas-climaticas/

14. Bustamante DM, Hernández MM, Torres N, Zúniga C, Sosa W, De Abrego V, et al. Information to act: Household characteristics are predictors of domestic infestation with the Chagas vector Triatoma dimidiata in central America. Am J Trop Med Hyg. 2015;93(1):97107.

15. INE. Caracterización departamental Jutiapa 2013. 2014.

16. Monroy, Mejia, Rodas, Rosales, Horio, Tabaru. Comaparasion of indoor searches with whole house demolition collections of the Vector Chagas disease and their indoor distribution. Japan Soc Med Entomol Zool. 1998;49(3):195-200.

17. Monroy C, Rodas A, Mejía M, Rosales R, Tabaru Y. Epidemiology of Chagas Disease in Guatemala: Infection Rate of Triatoma dimidiata, Triatoma nitida and Rhodnius prolixus (Hemiptera, Reduviidae) with Trypanosoma cruzi and Trypanosoma rangeli (Kinetoplastida, Trypanosomatidae). Mem Inst Oswaldo Cruz. 2003;98(3):305-10.

18. Pellecer MJ, Dorn PL, Bustamante DM, Rodas A, Monroy MC. Vector blood meals are an early indicator of the effectiveness of the ecohealth approach in halting chagas transmission in Guatemala. Am J Trop Med Hyg. 2013;88(4):638-44.

19. Soto JD, Monroy MC, Dorn P, Castellanos S, Lima R. Effect of community education in an integrate control for Triatoma dimidiata ( Hemiptera: Reduviidae) Efecto de la educación comunitaria para control integrado del Triatoma Dimidiata ( Hemiptera: Reduviidae ). Rev Cubana Med Trop. 2019;71(4):1-18.

20. Forsyth C, Meymandi S, Moss I, Cone J, Cohen R, Batista C. Proposed multidimensional framework for understanding Chagas disease healthcare barriers in the United States. PLoS Negl Trop Dis [Internet]. 2019;13(9):1-23. Available from: http://dx.doi.org/10.1371/journal.pntd.0007447

21. Echeverría LE, Marcus R, Novick G, Sosa-Estani S, Ralston K, Zaidel EJ, et al. WHF IASC roadmap on chagas disease. Glob Heart. 2020;15(26):1-31.

22. Rosales M. El trabajo en equipo multiprofesional e interdisciplinario. Rev Científica Salud Uninorte. 1999;14(1):46-52.

23. Molina-Marín G, Ramírez-Gómez A, Oquendo-Lozano T. Inter-sectorial and inter-institutional cooperation and coordination in public health within the market model of the colombian health care system, 2012-2016. Rev Salud Publica. 2018;20(3):286-92.

24. Cahan SH, Orantes LC, Wallin KF, Hanley JP, Rizzo DM, Stevens L, et al. Residual survival and local dispersal drive reinfestation by Triatoma dimidiata following insecticide application in Guatemala. Infect Genet Evol [Internet]. 2019;74(August):104000. Available from: https://doi.org/10.1016/j.meegid.2019.104000

25. Tabaru Y, Monroy C, Rodas A, Mejía M, Rosales R. The geographical distribution of vector of Chagas disease and population at risk of infection in Guatemala. Japa Soc Med Entomol Zool. 1999;50(1):9-17.

26. Dumonteil E, Gourbière S, Barrera-Pérez M, Rodriguez-Félix E, Ruiz-Piña H, Baños-Lopez O, et al. Geographic distribution of Triatoma dimidiata and transmission dynamics of Trypanosoma cruzi in the Yucatan Peninsula of Mexico. Am J Trop Med Hyg. 2002;67(2 SUPPL.):176-83.

27. Sarquis O, Borges-pereira J, Roberto J, Cord M, Gomes TF, Cabello PH, et al. Epidemiology of Chagas Disease in Jaguaruana , Ceará , Brazil . I . Presence of Triatomines and Index of Trypanosoma cruzi Infection in Four Localities of a Rural Area. Mem Oswaldo Cruz. 2004;99(May):263-70. 
28. Monroy C, Bustamante DM, Pineda S, Rodas A, Castro X, Ayala V, et al. House improvements and community participation in the control of Triatoma dimidiata re-infestation in Jutiapa, Guatemala. Cad saude publica / Minist da Saude, Fund Oswaldo Cruz, Esc Nac Saude Publica. 2009;25 Suppl 1:S168-78.

29. Castro-Arroyave D, Monroy MC, Irurita MI. Integrated vector control of Chagas disease in Guatemala: a case of social innovation in health. Infect Dis Poverty. 2020;9(1):1-9.

30. Monroy C, Rodas A, Mejiai M, Tabaru Y. Wall plastering and paints Chagas disease in Guatemala. Med Entomol Zool. 1998;49(3):187-93.

31. Rodriguez-Triana DR, Mertens F, Zúniga CV, Mendoza Y, Nakano EY, Monroy MC. The Role of Gender in Chagas Disease Prevention and Control in Honduras: An Analysis of Communication and Collaboration Networks. Ecohealth. 2016;13(3):535-48.

32. Barillas-Mendoza MF, López-Escobar MV. Determinación de la frecuencia de la enfermedad de Chagas en mujeres de edad fertil del municipio de Comapa, Jutiapa. Universidad de San Carlos de Guatemala; 2015.

33. Paz-Bailey G, Monroy C, Rodas A, Rosales R, Tabaru R, Davies C, et al. Incidence of Trypanosoma cruzi infection in two Guatemalan communities. Trans R Soc Trop Med Hyg. 2002;96(1):48-52.

34. Carias-Jimenez JL, Morales-Zepeda EN. Frecuencia de la enfermedad de Chagas en niños de 4 a 8 años de edad que asisten a escuelas públicas en 3 aldeas del municipio de Comapa, Jutiapa. Universidad de San Carlos de Guatemala; 2013.

35. Klein K, Burrone MS, Alonso JP, Ares LR, Martí SG, Lavenia A, et al. Estrategia para mejorar el acceso al tratamiento etiológico para la enfermedad de Chagas en el primer nivel de atención en Argentina. Rev Panam Salud Publica/Pan Am J Public Heal. 2017;41(4):1-8.

36. Olivera MJ, Porras villamil JF, Toquica Gahona CC, Rodriguez Hernandez JM. Barriers to diagnosis access for Chagas disease in Colombia. J Parasitol Res. 2018;1(Article ID 4940796):14.

37. Monroy C, Castrol X, Bustamante DM, Pineda S, Rodas A, Moguel B, et al. An Ecosystem approach for prevention of chagas disease in rural Guatemala. In: Springer, editor. Ecohealth research in practice [Internet]. Canada; 2012. p. 153-71. Available from: http://link.springer.com/10.1007/978-1-4614-0517-7

38. Fabbro DL, Streiger ML, Arias ED, Bizai ML, Del Barco M, Amicone NA. Trypanocide treatment among adults with chronic Chagas disease living in Santa Fe City (Argentina), over a mean follow-up of 21 years: Parasitological, serological and clinical evolution. Rev Soc Bras Med Trop. 2007;40(1):1-10.

39. Sosa-Estani S, Cura E, Velazquez E, Yampotis C, Segura EL. Etiological treatment of young women infected with Trypanosoma cruzi, and prevention of congenital transmission. Rev Soc Bras Med Trop. 2009;42(5):484-7.

\section{Figures}




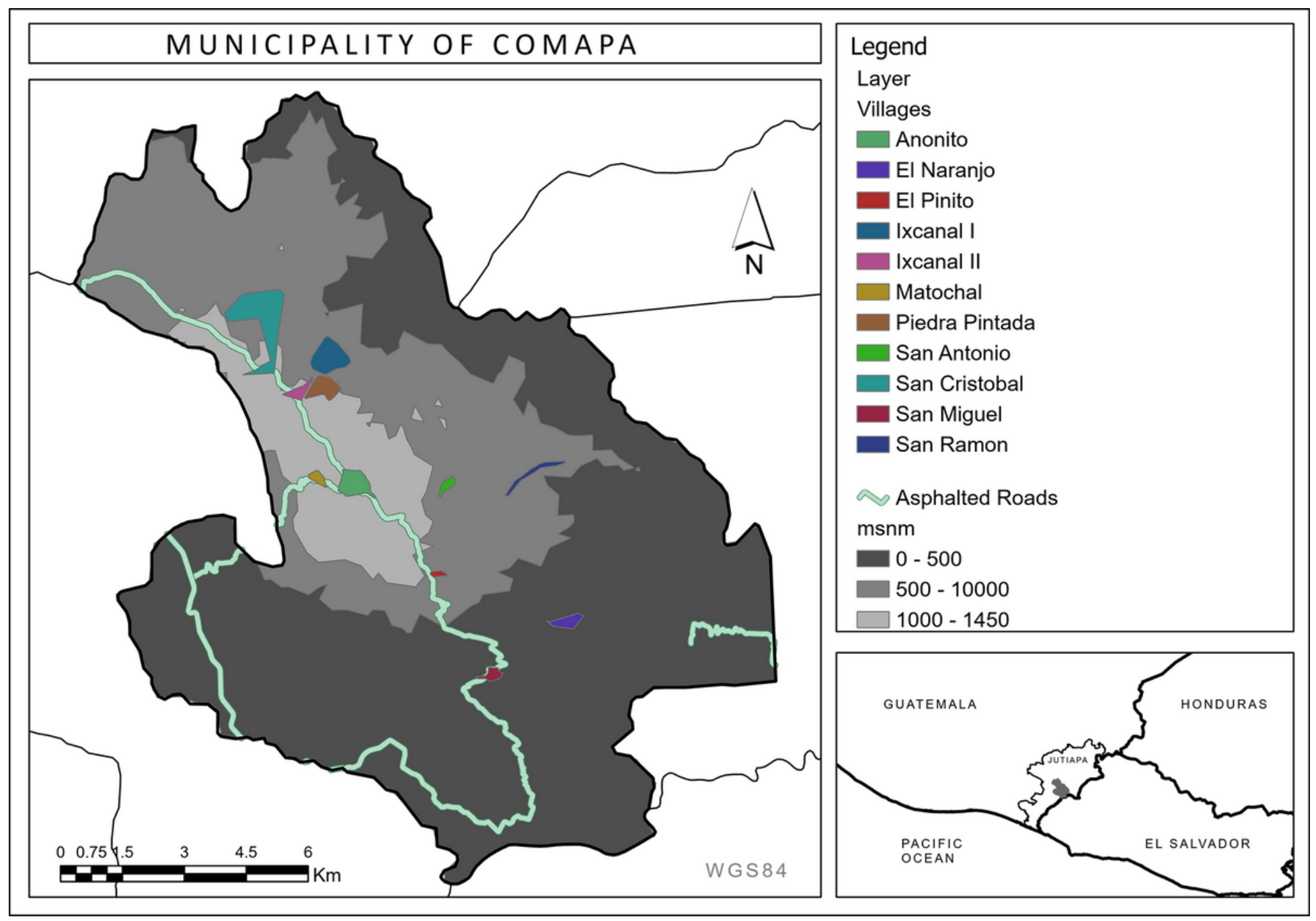

Figure 1

Study area. Showing the location of the 11 villages within the Municipality of Comapa and the location of the Municipality within the Department of Jutiapa and its location with respect to the country, bordering El Salvador, and the Pacific Ocean. Note: The designations employed and the presentation of the material on this map do not imply the expression of any opinion whatsoever on the part of Research Square concerning the legal status of any country, territory, city or area or of its authorities, or concerning the delimitation of its frontiers or boundaries. This map has been provided by the authors. 